\title{
Fault Detection and Management of the Three-Phase 4-Leg Voltage Source Inverter
}

\author{
Mi Tang, Pericle Zanchetta \\ The University of Nottingham, \\ University Park \\ Nottingham, UK
}

\author{
M. di Benedetto, A. Lidozzi, L. Solero \\ Roma Tre University \\ C-PED, Center for Power Electronics and Drives \\ Roma, Italy
}

\begin{abstract}
A novel fault detection and ride-through method for the three-phase 4-Leg Inverter (3Ф4L Inverter) used in off-grid applications is addressed in this paper. Open circuit and short circuit faults of the power devices located in the 3Ф4L Inverter have been theoretically analyzed. Hence, the fault detection and converter protection strategy has been implemented using a combination of a resonant controller in the $\alpha \beta$ frame and a repetitive observer. The proposed strategy has been at first validated by means of simulation results performed in MATLAB/Simulink environment. The fault detection and ridethrough algorithm has been then implemented in FPGA using LabVIEW environment and full experimental verification are performed on the prototype of the three-phase 4-leg inverter.
\end{abstract}

Index Terms - resonant controllers, disturbance observer, threephase four-leg inverter, fault detection.

\section{INTRODUCTION}

In the modern society, three-phase inverters are widely used in all areas, such as power supplies for industrial applications, medical equipment, traction devices, household appliances, distributed generation system, etc. [1]-[3]. In this latter application, for off grid systems, the $3 \Phi 4 \mathrm{~L}$ Inverter is controlled to have high quality voltage waveforms to supply local loads. The main feature of a $3 \Phi 4 \mathrm{~L}$ inverter is to maintain the desired sinusoidal output voltage waveform over all loading conditions (linear and non-linear loads). Furthermore, the continuity of operation is a key feature of the power converter, even in case of faults. Consequently, since the power semiconductors are very sensitive to failures, it is vital to improve the reliability of the power conversion system. In practical operations, the $3 \Phi 4 \mathrm{~L}$ inverter can suffer from various faulty conditions [4], in which the open-circuit and short-circuit faults of the power semiconductors, as well as the short-circuit at load side are the severest cases for inverters [5]. Thus, without proper fault detections and protections, the power semiconductor devices might be irreversibly damaged. According to the nature of the failures, a fault diagnosis is needed and, to minimize the likelihood of any damage, the processing time of the fault diagnosis must be reduced. Especially for the power semiconductor short-circuit fault, the detection and isolation actions must be performed as fast as possible to protect the DClink and the silicon chips. Many investigations on fault diagnosis of semiconductor devices located in the converter have been performed in literature [6]-[16]. Several fault diagnostic techniques are based on adding a further circuity to protect the power semiconductors [6]-[11]. In this case, the switches are protected in less than $10 \mu$ s by an additional analog circuit implemented in the gate drivers. In [9] and [10] a redundant fourth-leg and additional devices have been added to the NPC converter in order to obtain fault-tolerant capability. The fault detection method proposed in [11] identifies the location of the faulty switch and the faulty clamping diode of the NPC inverter without any additional hardware or complex calculations. In [12] and [13] the short-circuit faults of the power semiconductors are managed by adding a parallel converter. In [14] an appropriate control strategy is used to detect and isolate the open- and short-circuit faults. Here too, redundant switches are used to manage the faults. A predictive control algorithm and a fault detection method for current sensors in a three-phase four leg inverter has been proposed in [15]. In this case, the fault detection operates in $d q$ domain, and the implementation of the control algorithm and fault detection method is implemented on a FPGA. In [16] the voltage waveform is examined to identify fault type and location. Here, the faults can be found and managed by changing the current path or using a redundant power semiconductor thanks to the comparison between the fault indicators and the threshold voltage. As it can be noticed, the techniques used in [6]-[11] can detect the fault in a few microseconds at the most (up to $10 \mu \mathrm{s}$ ) after the initial fault, in the other techniques [13]-[16] the fault is discovered in a time between $10 \mu$ s and $100 \mathrm{~ms}$ after the initial fault. Thus, the faults can be defined on short-term time scale and long-term time scale [16]. Several fault diagnosis methods for power conversion system are able to detect the fault by analyzing the distortion of the output currents [7], [17]-[19]. In [17]-[19] the output currents are analyzed using different methods, such as ark's transformation, normalized average current method, slope method, etc.

In this paper a novel fault detection and converter protection strategy for the 3Ф4L Inverter has been proposed. The detection strategy has been tailored in order to identify the power semiconductor fault and manage it, leading the converter in a safe operating condition. The proposed detection strategy is based on resonant controller in $\alpha \beta$ domain plus a repetitive observer. The proposed technique allows to detect the faults at the latest within half of the switching period, which means that, for a switching frequency $f_{s w}$ equal to $12 \mathrm{kHz}$, the faults are detected in $83.33 \mu \mathrm{s}$. Such reduced times are achieved thanks to the implementation based on a Field Programmable Gate Array (FPGA).

\section{SWITCHES FAULT ANALYSIS OF THE 3Ф4L INVERTER}

This section discusses the 3Ф4L Inverter behavior under switches malfunctions in short circuit and open circuit modes. Figure 1 shows the circuit diagram of the 3Ф4L Inverter. This topology consists of a three-phase inverter plus an additional leg. The AC side is connected to the output filter and load. The 
3Ф4L Inverter has 16 different switching states in which two (00000 and 1111) states are redundant. However, the $3 \Phi 4 \mathrm{~L}$ converter can be considered as three-single phase inverters. The driver misfiring or the bonding wire failure can cause the open circuit faults of the MOSFETs or IGBTs, while the short circuit fault of the power devices can be produced by the malfunctions of the gate driver circuit [8].

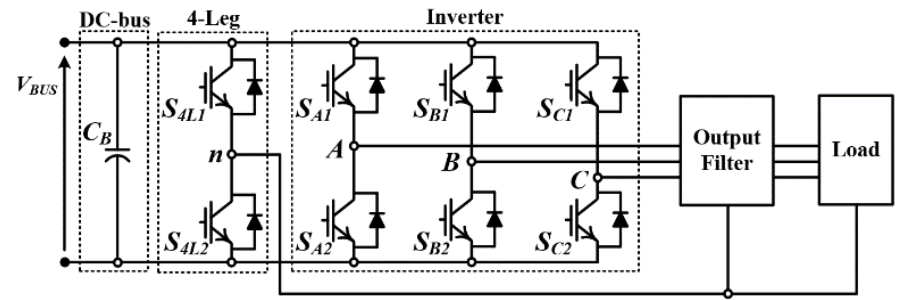

Figure 1: 3థ4L Inverter topology.

\section{A. Open Circuit faults}

Given the symmetry of the structure, only the phase leg A is considered. Assuming the positive current into the single-phase A, the current flows through the switch $S_{A I}$ and $S_{4 L 2}$ (or diode $D_{4 L I}$ ), as shown in Figure 2. When the open circuit fault occurs at the device $\mathrm{S}_{\mathrm{A} 1}$, immediately the phase current $\mathrm{A}$ goes to zero, as illustrated in Figure 3.

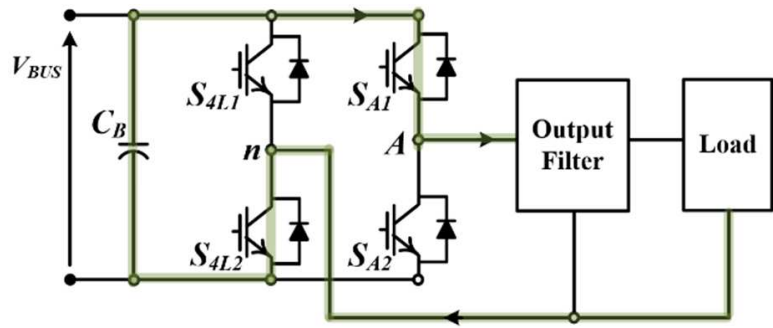

Figure 2: Circuit of the single-phase inverter during the positive current.

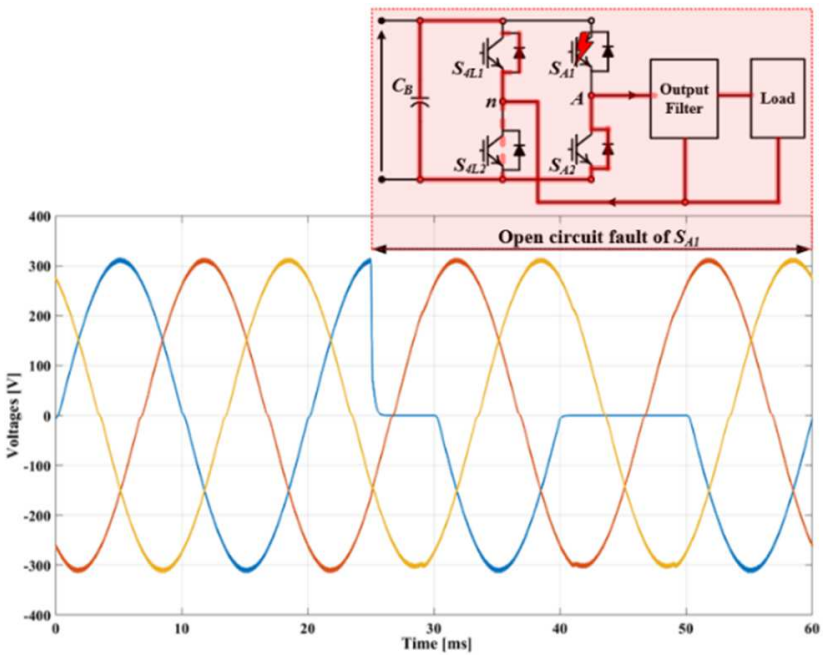

Figure 3: Three-phase voltage waveforms: open circuit fault of $\mathrm{S}_{\mathrm{A1}}$.

In this condition, the fault current flowing in the devices $\mathrm{D}_{\mathrm{A} 2}-$ $\mathrm{S}_{4 L 2}$ or $\mathrm{C}_{\mathrm{B}}-\mathrm{D}_{\mathrm{A} 2}-\mathrm{D}_{\mathrm{A} 4 \mathrm{~L} 1}$ (path highlighted in red in Figure 3) may damage these switches and eventually lead to destruction of the entire power converter. When the fault occurs to the diode $D_{A l}$, the device $S_{A 2}$ is in the turn-on state also during the dead time (DT), so the voltage waveform is heavily distorted, as illustrated in Figure 4. A similar situation occurs during the negative phase current. Figure 5 shows the current path during normal operation.

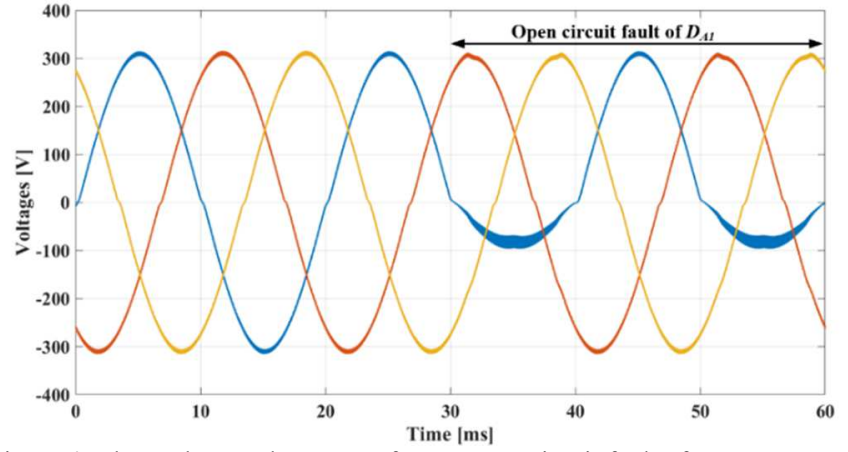

Figure 4: Three-phase voltage waveforms: open circuit fault of $D_{A l}$.

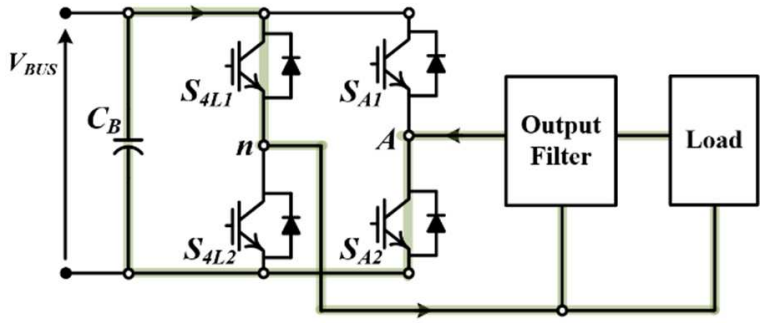

Figure 5: Circuit of the single-phase inverter during the negative current.

As soon as the open circuit fault of the $S_{A 2}$ happens, the phase current goes to zero, as illustrated in Figure 6, and starts to flow in the $D_{A 1}-S_{4 L I}$ or $C_{B}-D_{A 1}-D_{4 L 2}$.

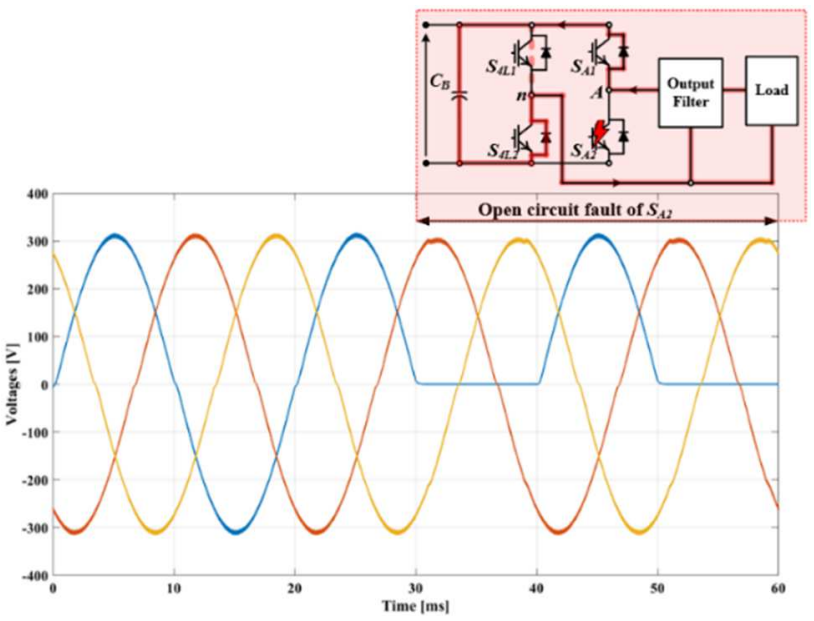

Figure 6: Three-phase voltage waveforms: open circuit fault of $S_{A 2}$.

This situation might cause the destruction of the converter. The device $S_{A I}$ is in the turn-on state during the dead time (DT) when the fault of $D_{A 2}$ occurs, thus the voltage waveform is strongly distorted, as shown in Figure 7.

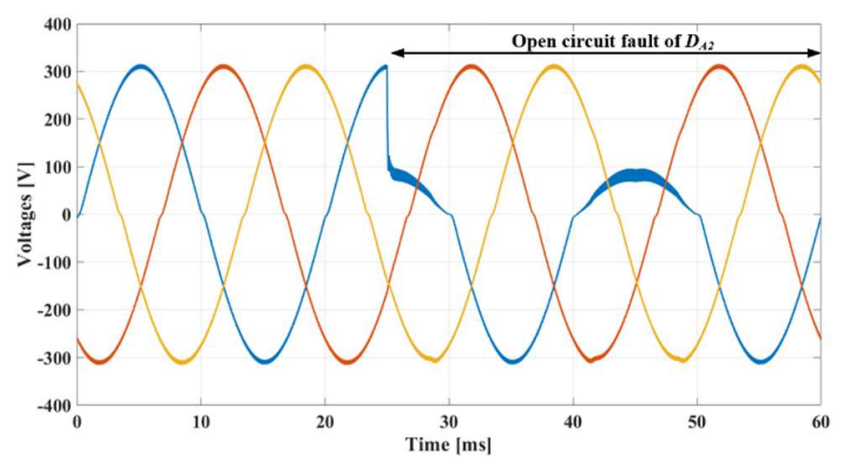

Figure 7: Three-phase voltage waveforms: open circuit fault of $D_{A 2}$. 
The open circuit fault of $S_{4 L I}$ as well as the open circuit fault of $D_{4 L 1}$ (or $S_{4 L 2}-D_{4 L 2}$ ) cause the presence of an offset in the phase voltage waveforms, as shown in Figure 8. It can be seen that the neutral point $n$ is connected to the positive or negative bus according to the fault of $S_{4 L I}$ or $S_{4 L 2}$, so only the half DC-link is considered.

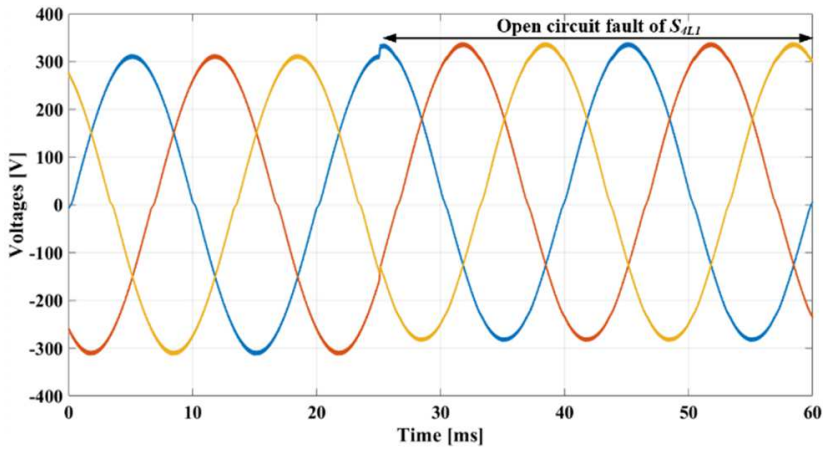

(a)

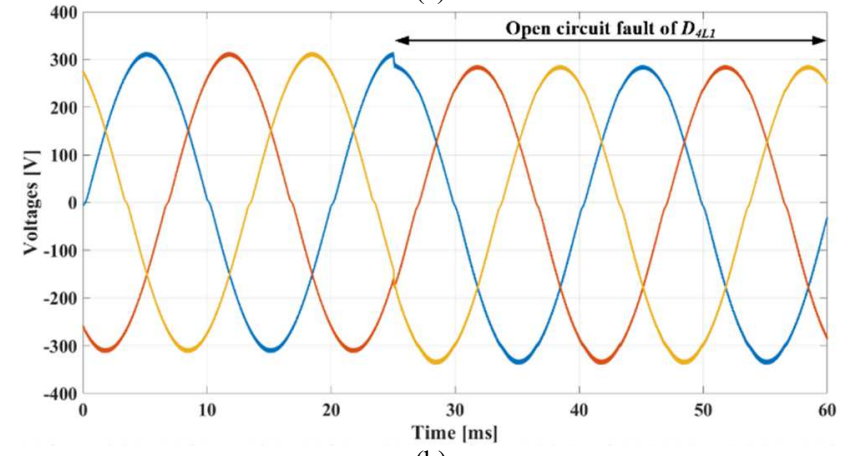

(b)

Figure 8: Three-phase voltage waveforms, open circuit fault of a) $S_{4 L I}$ and b) $D_{4 L 1}$.

\section{B. Short Circuit faults}

Assuming that the load current is positive (flowing out of the converter), the diode $D_{A 2}$ is carrying the load current. Then the IGBT $S_{A 1}$ is turning-on and the diode $D_{A 2}$ is turning-off. If the switch $S_{A l}$ fails in short-circuit, the fault must be detected and cleared by turning-off the switch $S_{A 2}$ to avoid the short circuit of the DC-bus, which can cause the explosion of the converter. Figure 9 shows the voltage waveforms during the short circuit fault of $S_{A 1}$.

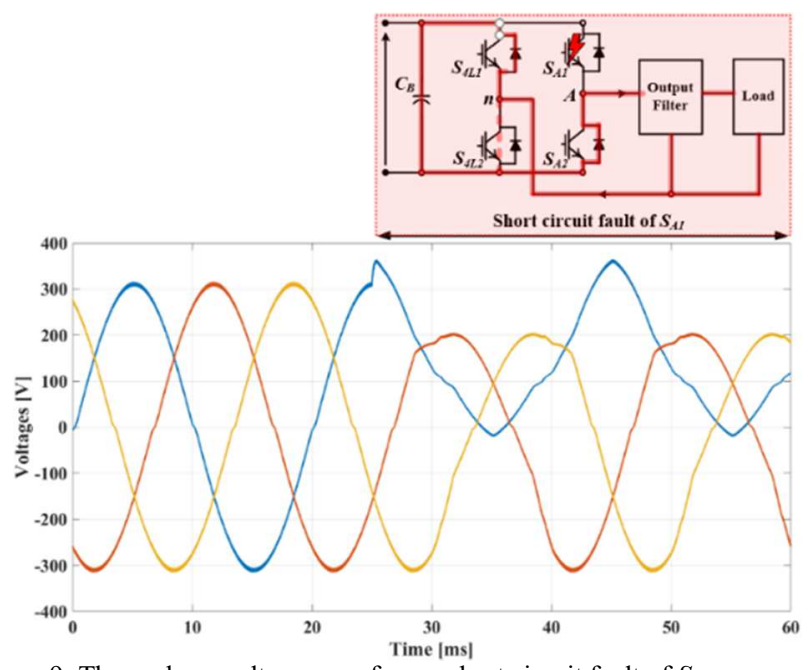

Figure 9: Three-phase voltage waveforms, short circuit fault of $S_{A 1}$.

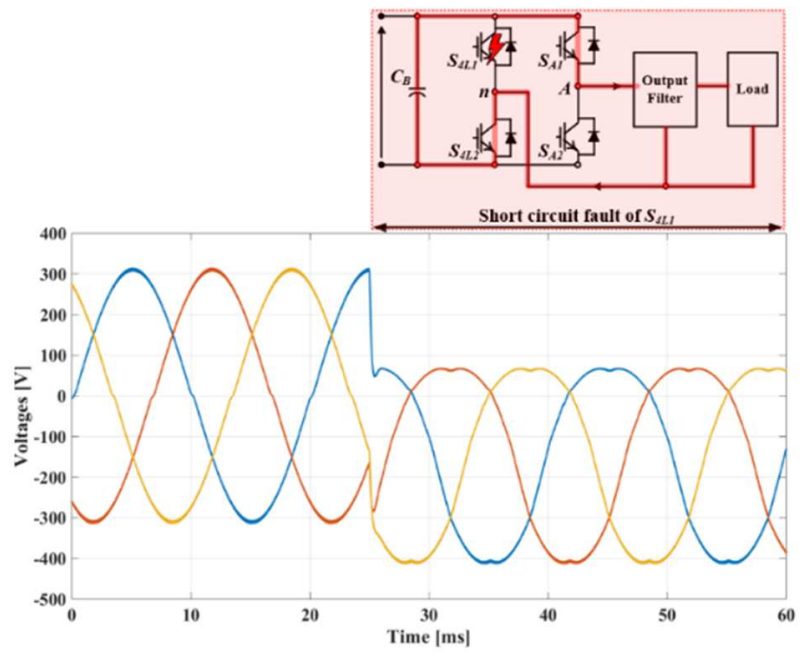

Figure 10: Three-phase voltage waveforms, short circuit fault of $S_{4 L 1}$.

However, the switch $S_{A 2}$ remains short circuited. It creates an asymmetric short circuit via the remaining healthy diodes $D_{A 2}$ and 4-Leg. The equivalent circuit diagram is depicted in Figure 9 . The fault current can be significantly higher than the nominal current. It may cause the explosion of the switch $S_{A 2}$ and eventually the failure of the entire power converter. A dual situation happens when the switch $S_{A 2}$ fails in short-circuit. When the short circuit fault of the $S_{4 L I}$ (or $S_{4 L 2}$ ), the neutral point $n$ is connected to the positive DC-link (or negative DC-link); thus, the voltage waveforms appear to be asymmetrical as shown in Figure 10. The review of the power device faults, and the behavior of the converter are summarized in Table I.

Table I. Faults summary on the half circuit of the $4 \mathrm{~L}$ Inverter.
\begin{tabular}{|c|c|c|}
\hline Fault & Converter behavior & Condition \\
\hline \multicolumn{3}{|c|}{ Open-Circuit } \\
\hline$S_{A 1}$ & The positive voltage waveform is missing & Dangerous \\
\hline$D_{A 1}$ & The negative voltage waveform is distorted & Dangerous \\
\hline$S_{A 2}$ & The negative voltage waveform is missing & Dangerous \\
\hline$D_{A 2}$ & The positive voltage waveform is distorted & Dangerous \\
\hline$S_{4 L 1}, S_{4 L 2}$ & Positive offset in the voltage waveform & Quasi-normal \\
\hline$D_{4 L L}, D_{4 L 2}$ & Negative offset in the voltage waveform & Quasi-normal \\
\hline \multicolumn{3}{|c|}{ Short-Circuit } \\
\hline$S_{A 1}, D_{A 1}$ & high distortion of the voltage waveform & Catastrophic \\
\hline$S_{A 2}, D_{A 2}$ & high distortion of the voltage waveform & Catastrophic \\
\hline$S_{4 L 1}, S_{4 L 2}$ & Asymmetrical voltage waveform & Catastrophic \\
$D_{4 L 1}, D_{4 L 2}$ & \\
\hline
\end{tabular}

As it can be easily seen, the converter can continue to feed the load when the open-circuit fault happens to the power semiconductors located in the fourth leg. In other cases, the faults can seriously damage the converter.

\section{FAULt DETECTION AND MANAGEMENT}

This section discusses at first the fault detection strategy, followed by, the proposed control structure aimed to manage the fault. The fault detection algorithm is shown in the flow chart of Figure 11. As it can be seen, the acquired voltages and currents are compared in each switching period with the threshold phase voltage, $\pm V_{p, h}$, the threshold phase current, $\pm i_{p, h}$, and the threshold switching voltage, $\pm V_{s w, h}$. When the measured phase-to-neutral voltages, currents and phase-to-neutral switching voltages are different from zero or do not exceed the relative thresholds, the Open-Circuit Fault Indicator (OCFI) and/or the Short-Circuit Fault Indicator (SCFI) is set at low 
value. In other words, monitoring the phase voltages before and after the filter, as well as the phase currents, it is possible to understand which device is faulty. For instance, when the opencircuit fault happens at $S_{x l}$ (or $S_{x 2}$ ), with $x \in\{A, B, C\}$, the phaseto-neutral voltage and current waveforms go to zero and the phase-to-neutral switching voltage is different from zero for half of the fundamental period, as illustrated in Figure 3 and Figure 6. In this case, the open-circuit fault of $S_{x 1}$ (or $S_{x 2}$ ) is detected and the $\mathrm{OCFI}_{S x I}$ is set at high value.

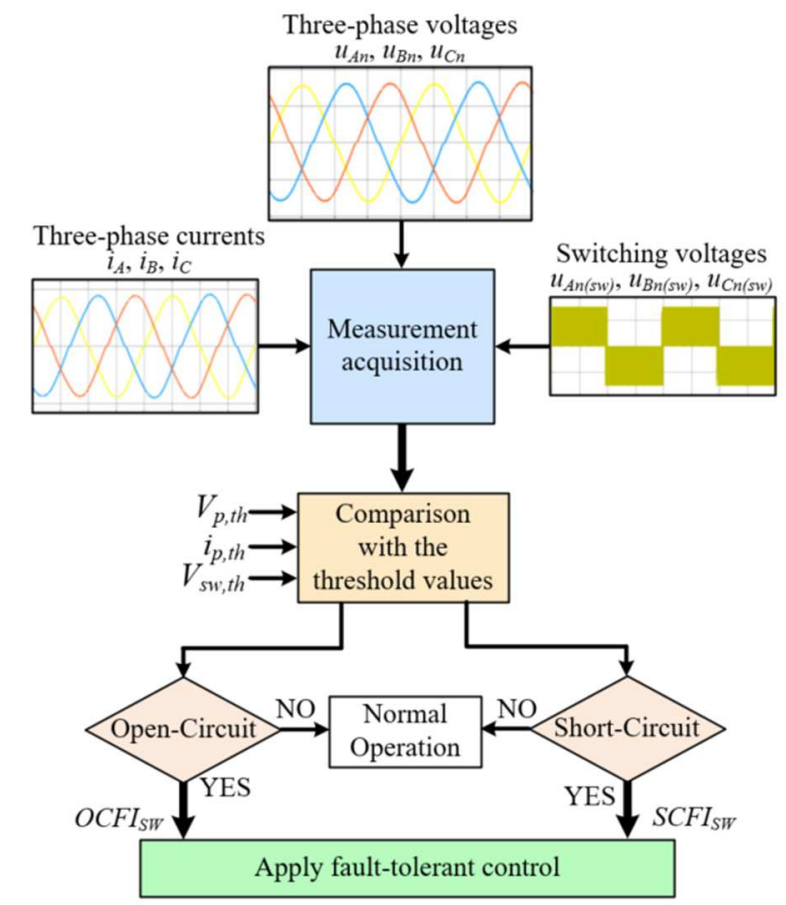

Figure 11: Block scheme of the fault detection algorithm.

The open-circuit fault of the diodes $D_{x I}$ (or $D_{x 2}$ ) is easy to be recognized since the phase voltage waveform of the faulty leg does not exceed a certain voltage value, as shown in Figure 5 and Figure 7. Thus, when the phase voltage waveform is within the voltage range $\pm \sqrt{2} U_{r m s}$, where $U_{r m s}$ is RMS phase voltage, the $\mathrm{OCFI}_{D x l}$ (or $\mathrm{OCFI}_{D x 2}$ ) is set at low value. The open-circuit fault of the switch $S_{4 L 1}$ (or $S_{4 L 2}$ ) and diode $D_{4 L 1}$ (or $D_{4 L 2}$ ) is detected after one fundamental period how it is explained later. If the phase voltage waveforms never reach the negative peak value (or the positive peak value) an open-circuit fault at $S_{4 L 1}$ (or $S_{4 L 2}$ ) occurs, as illustrated in Figure 8a and a relative fault indicator $\mathrm{OCFI}_{S 4 L 1}$ (or $\mathrm{OCFI}_{S 4 L 2}$ ) is set at high value. The short circuit fault at $S_{x l}\left(\right.$ or $S_{x 2}$ ) can be detected as soon as the faulty phase exceeds the peak value and the other phase do not reach the peak value, as shown in Figure 9, so that the fault indicator $\mathrm{SCFI}_{S x I}$ (or $\mathrm{SCFI}_{S x 2}$ ) is set at high value. Finally, the open short circuit fault at $S_{4 L 1}$ (or $S_{4 L 2}$ ) can be detected by monitoring the three-phase voltage waveforms since the voltages never reach the positive peak value.

Once a fault is detected, the faulty switch will be forced open, and a repetitive observer ( $\mathrm{RO}$ ) based compensation will be activated. Although the three phase voltages during the above faults may not be maintained, it is possible to maintain the postfault alpha-beta voltage as the same as in pre-fault condition, such that the output voltage vector of the $3 \Phi 4 \mathrm{~L}$ inverter is not affected by the fault. The proposed control scheme is shown in
Figure 12. As it can be seen from Figure 12, two resonant controllers, as proposed in [20], are used to regulate the alphabeta voltage, respectively. A RO proposed in [21] is used to observe the zero sequence in the feedback voltage and inject the same zero sequence component in the $3 \Phi 4 \mathrm{~L}$ inverter.

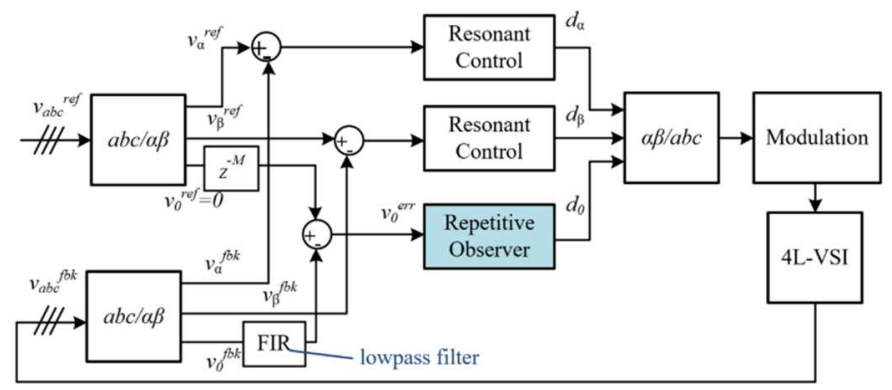

(a)

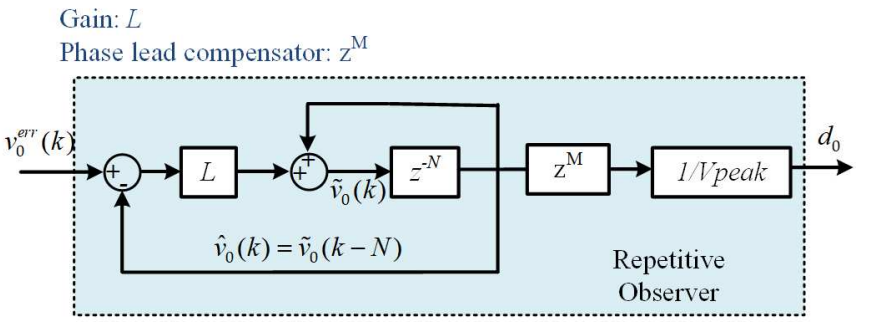

(b)

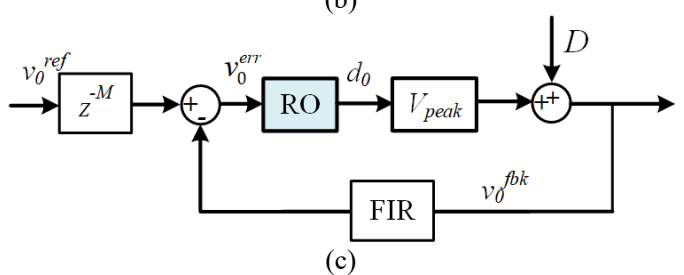

Figure 12: The proposed control scheme: a) whole control system, b) repetitive observer, c) equivalent diagram for zero-sequence control.

The zero-sequence voltage is regulated to reconfigure the voltage vector during faults at steady state. The equation for the RO is given in (1).

$$
R O(z)=\frac{L z^{-N+M}}{V_{\text {peak }}\left[1+(L-1) z^{-N}\right]}
$$

Where, $L=0.9$ is the gain of the RO, the delay length $N$ is the ratio between the sampling frequency (e.g. $12 \mathrm{kHz}$ ) and the fundamental frequency (i.e. $50 \mathrm{~Hz}$ ), $V_{\text {peak }}$ is the peak value of the grid phase voltage. $M$ equals the length delay caused by the lowpass finite impulse response (FIR) filter in Figure 12. In this work, the FIR filter is chosen to be $15^{\text {th }}$ order one and its cut-off frequency is $250 \mathrm{~Hz}$. Therefore, $M=15$. Space vector pulse width modulation (SVPWM) technique is implemented in the modulation block in Figure 12. Hence, third harmonic will be injected in the zero-sequence voltage, $\mu$ and which $i \mu$ within the passband of the FIR filter.

The zero-sequence voltage control is decoupled with the alphabeta voltage control, its equivalent diagram is drawn in Figure 12 , where, in healthy condition, $D$ contains the third harmonics injected by the SVPWM and some high frequency measurement noises. In faulty condition, $D$ contains also the zero-sequence voltage induced by the fault.

When per unit values are used, $V_{\text {peak }}=1$. The bode plot of the $\mathrm{RO}$ is shown in Figure 13. As it can be seen, the RO tracks components of $50 i \mathrm{~Hz}(i=0,1, \ldots 1200)$ in $v_{0}{ }^{\text {err }}$, i.e. all harmonics 
in the zero-sequence voltage, up to the Nyquist frequency. The FIR removes high frequency components in $v_{0}^{\text {err }}$, thus prevents the RO from tracking the high frequency components.

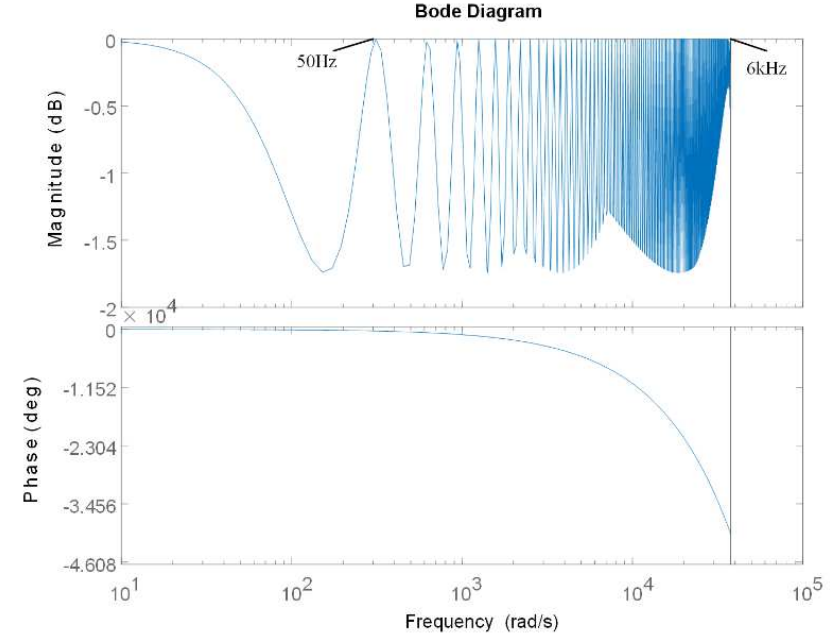

Figure 13: Bode plot of RO.

\section{Simulation Results}

The proposed control strategy has been verified by means of a digital-switching model realized in Matlab/Simulink. The 3Ф4L Inverter has been simulated using the parameters listed in Table II.

Table II Operating point of the of 3థ4L Inverter.

\begin{tabular}{|l|l|}
\hline DC-link voltage $V_{D C}$ & $750 \mathrm{~V}$ \\
\hline phase-to-neutral RMS voltage $u_{x n}$ & $220 \mathrm{~V}$ \\
\hline switching frequency $f_{s w}$ & $12 \mathrm{kHz}$ \\
\hline fundamental frequency $f_{0}$ & $50 \mathrm{~Hz}$ \\
\hline dead-time & $2 \mu \mathrm{s}$ \\
\hline
\end{tabular}

Figure 14 illustrates the three-phase voltages $u_{A n}, u_{B n}, u_{C n}$, the three-phase currents $i_{A}, i_{B}, i_{C}$ and the phase-to-neutral switching voltage $u_{A n(s w)}$ under open-circuit fault of the switch $S_{A I}$. As it can be noticed, as soon as the fault happens, the proposed algorithm is able to detect the fault and the OCFI related to the switch $S_{A I}$ changes from low to high value.
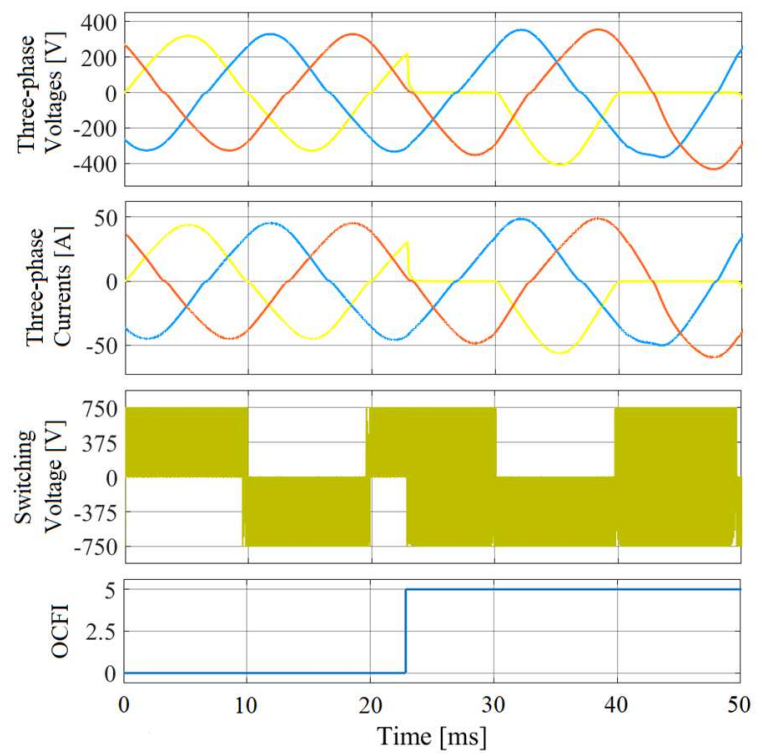

Figure 14: Three-phase voltages $u_{A n}, u_{B n}, u_{C n}$, three-phase currents $i_{A}, i_{B}, i_{C}$, phase-to-neutral switching voltage $u_{A n(s w)}$ and $O C F I$ under open-circuit fault in $S_{A 1}$.
In this case, the detection algorithm checks both the phase

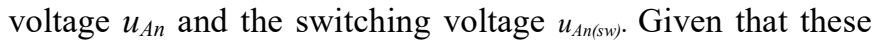
voltages are in different sector compared to normal operating condition, the fault of the device is detected. In fact, the phase voltage $u_{A n}$ goes to zero and the voltage across the switch $S_{A I}$ is equal to the DC-link voltage $V_{D C}$ instead of zero, as it is evident from the switching voltage in Figure 14. Figure 15 shows the voltage and current waveforms under short-circuit fault in $S_{A I}$.
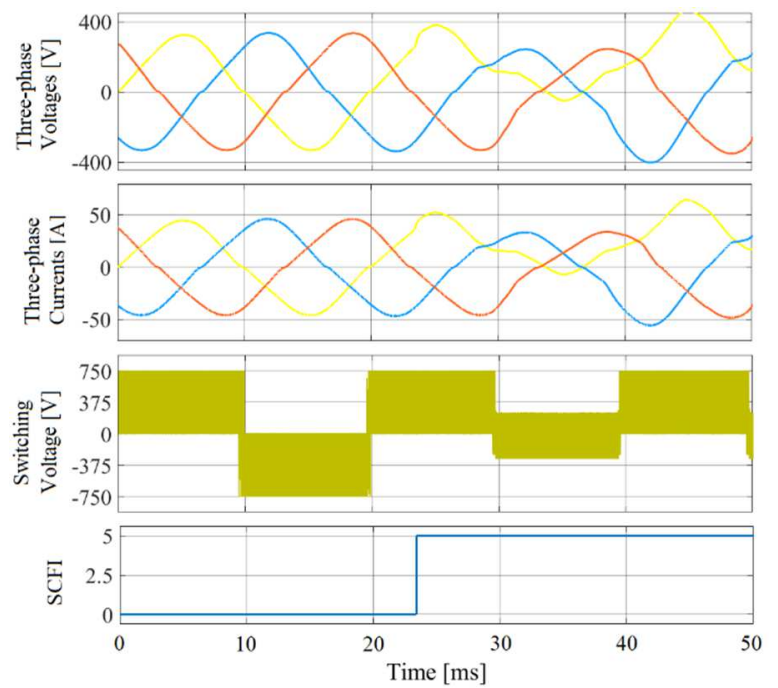

Figure 15: Three-phase voltages $u_{A n}, u_{B n}, u_{C n}$, three-phase currents $i_{A}, i_{B}, i_{C}$, switching voltage $u_{A n(s w)}$ and $S C F I$ under short-circuit fault in $S_{A I}$.

Here, the fault detection algorithm can identify the fault as soon as it occurs too and the fault indicator SCFI, related to the switch $S_{A I}$, is set at high value. In both cases, the open-circuit and the short circuit of the switch $S_{A l}$ is detected within the switching period. The open-circuit fault of $S_{4 L 1}$ (or $S_{4 L 2}$ ) is detected in one fundamental period as illustrated in Figure 16. This fault is very difficult to detect due to the converter behavior that is very similar to the normal operation.
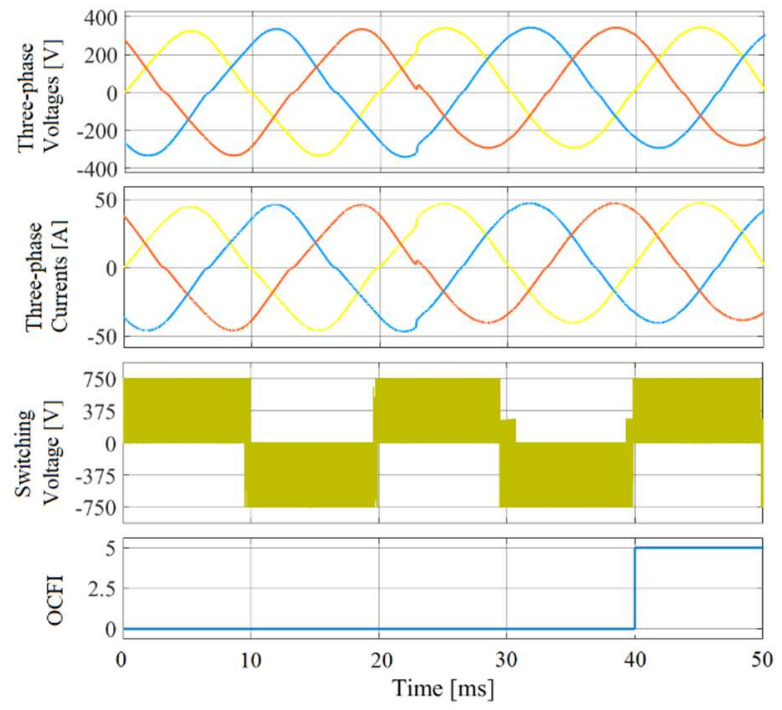

Figure 16: Three-phase voltages $u_{A n}, u_{B n}, u_{C n}$, three-phase currents $i_{A}, i_{B}, i_{C}$, phase-to-neutral switching voltage $u_{A n(s w)}$ and $O C F I$ under open-circuit fault in $S_{4 L I}$.

In this condition, the algorithm checks whether the phase voltage and current waveforms reach their maximum peak in 
the fundamental period. Since the voltage and current waveforms never reach the negative peak and exceed the positive peak in case of $S_{4 L 1}$ fault (or the voltage and current waveforms never reach the positive peak and exceed the negative peak in case of $D_{4 L 1}$ fault), in the following fundamental period the fault is detected by enabling the $O C F I$ related to the switch $S_{4 L I}$ (or $D_{4 L 1}$ ), as illustrated in Figure 16. The short-circuit of the device $S_{4 L 1}$ is immediately detect since the phase voltage $u_{x n}$ and the phase-to-neutral switching voltage $u_{x n(s w)}$ are in different sector from the normal operation condition and the fault indicator is set at high value.
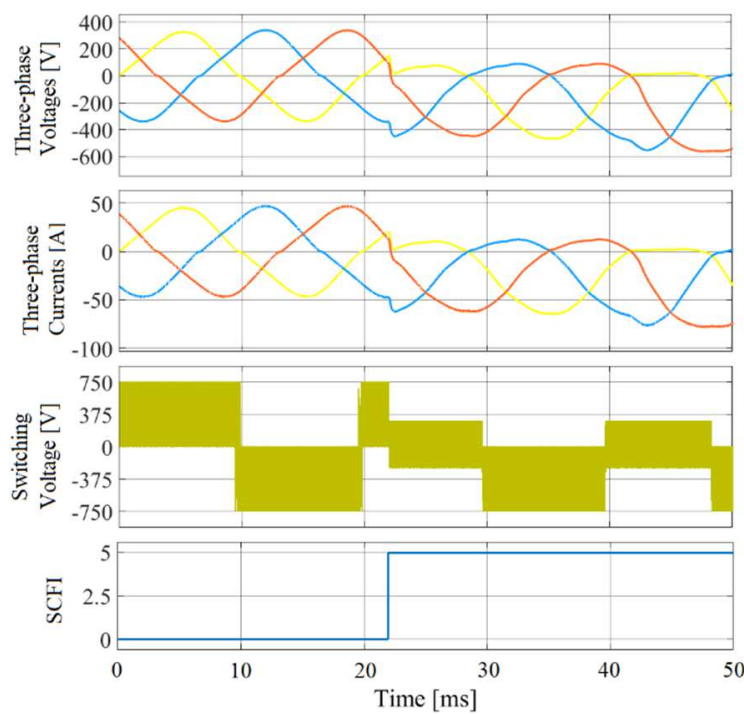

Figure 17: Three-phase voltages $u_{A n}, u_{B n}, u_{C n}$, three-phase currents $i_{A}, i_{B}, i_{C}$, phase-to-neutral switching voltage $u_{A n(s w)}$ and SCFI under short-circuit fault in $S_{4 L 1}$.
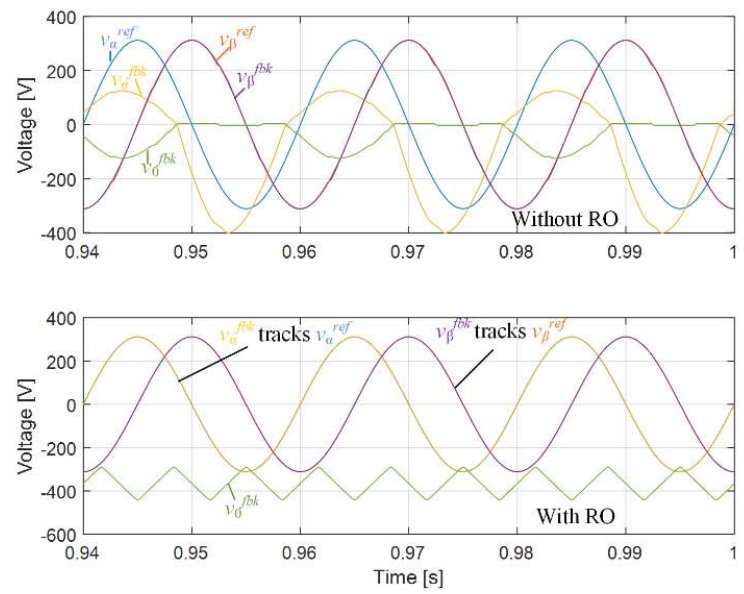

Figure 18: Open circuit fault management of $S_{A 1}$ : with/without RO for zero sequence injection.

When the open circuit fault of $S_{A l}$ occurs, the $v_{\alpha}, v_{\beta}$, and the zero-sequence voltage $v_{0}$ with and without RO are compared in Figure 18. The results indicate that, with $\mathrm{RO}$ to regulate the zero-sequence voltage, the alpha-beta voltage can track the reference as if there is no fault. Figure 19 shows the voltage waveforms when open circuit faults happen at both $S_{A 1}$ and $S_{B 1}$. As it is shown, $v_{\alpha}, v_{\beta}$ are maintained with RO. The voltage waveforms when both $S_{A 1}$ and $S_{A 2}$ are open and when $S_{4 L 1}$ is open are shown in Figure 20 and Figure 21, respectively. According to Figure 21, the alpha and beta voltages are maintained both with and without $\mathrm{RO}$, so it is optional to activate RO or not in this case. The short-circuit faults of any power semiconductors have strong impact on the converter, leading to high short-circuit current flowing in both the power switches and DC-bus capacitors. In this case, the control algorithm is able to identify and to isolate the faulty leg, as well as to change the current path into the healthy leg.
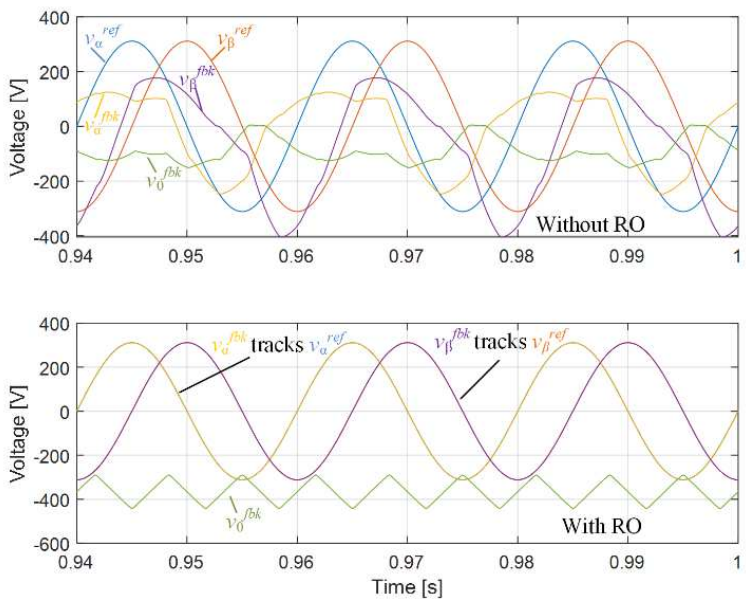

Figure 19: Open circuit fault management of $S_{A I}$ and $S_{B I}$ : with/without RO for zero sequence injection.
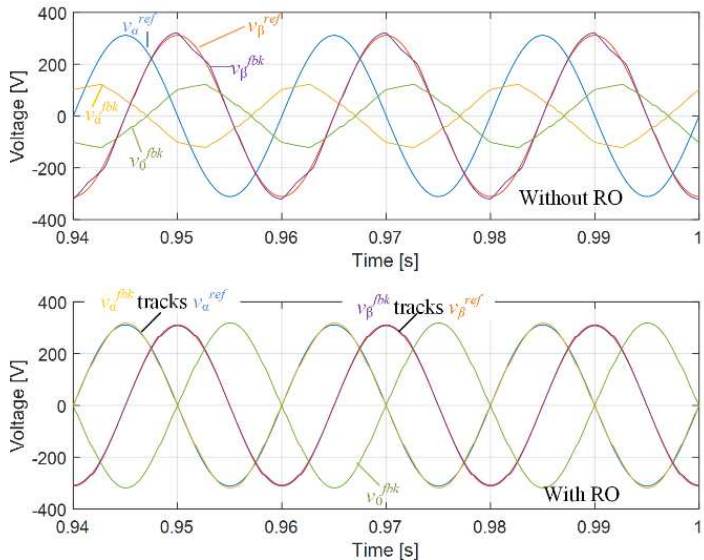

Figure 20: Open circuit fault management of $S_{A 1}$ and $S_{A 2}$ : with/without RO for zero sequence injection.
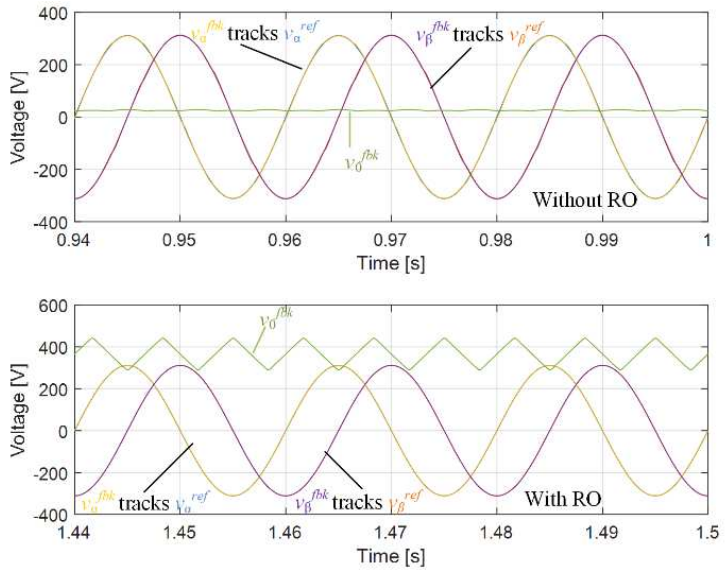

Figure 21: Open circuit fault management of $S_{4 L I}$ : with/without RO for zero sequence injection.

\section{EXPERIMENTAL RESULTS}

Experimental tests have been performed to verify the validity and effectiveness of the proposed fault detection and control 
algorithm. The proposed fault detection and control algorithm have been implemented in LabVIEW environment and it has been tested on the prototype of $3 \Phi 4 \mathrm{~L}$ Inverter with a suitably designed output filter [22], as shown in Figure 22.

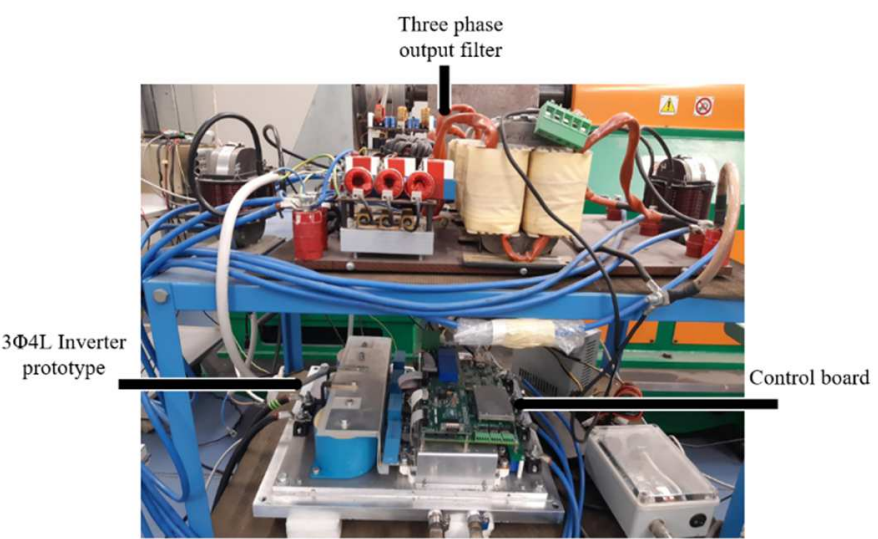

Figure 22: 3థ4L Inverter prototype with the three-phase output filter.

Looking at the figure, it is possible to recognize the $3 \Phi 4 \mathrm{~L}$ Inverter, the filter board and the control board which are based on the National Instruments sbRIO-9651 System on Module (SoM) [23]. The converter has been built using four SEMIX module (SEMIX303GB12Vs) 300A-1200V. The prototype of the converter has been tested considering the DC-link voltage $V_{D C}=400 \mathrm{~V}$, the phase-to-neutral RMS voltage $u_{x n}=220 \mathrm{~V}$, the switching frequency $f_{s w}=12 \mathrm{kHz}$ and the fundamental frequency $f_{0}=50 \mathrm{~Hz}$. The DC-link voltage has been kept at $400 \mathrm{~V}$ by the multi-port DAB converter available in the laboratory [24]. Voltage and current waveforms are investigated using the Yokogawa DL9140 oscilloscope. Figure 23 shows the phaseto-neutral switching voltage $u_{A n(s w)}$, the phase-to-neutral voltages $u_{A n}, u_{B n}$, the phase current $i_{A}$, under open-circuit fault at $S_{A I}$.

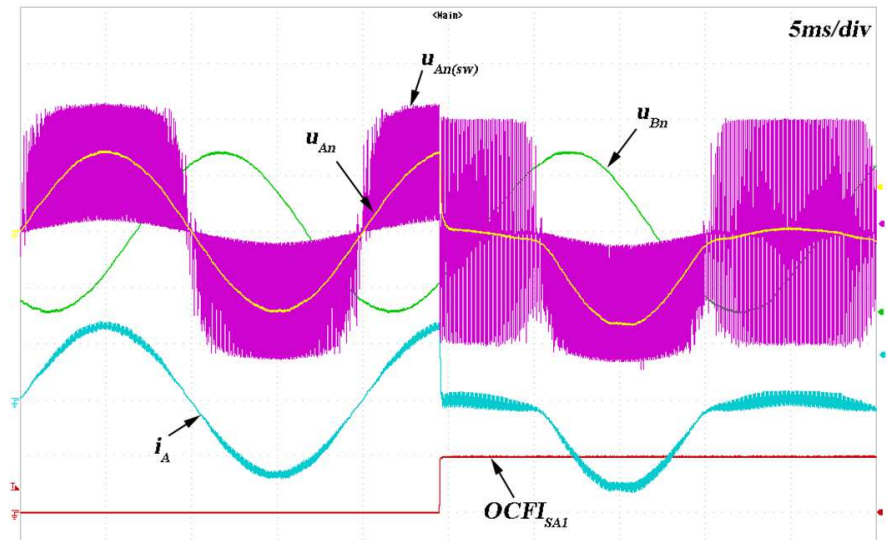

Figure 23: Waveforms under open-circuit fault in $S_{A l}$ : a) phase-to-neutral switching voltage $u_{A n(s w)}($ violet trace, $200 \mathrm{~V} / \mathrm{div})$, b) phase-to-neutral voltages $u_{A n}, u_{B n}$ (yellow trace and green trace, $200 \mathrm{~V} / \mathrm{div}$ ), c) phase current $i_{A}$, (cyan trace, 20A/div), d) OCFI (red trace 5V/div).

As it can be seen, the positive phase current and the positive phase-to-neutral voltage $u_{A n}$ go to zero and the voltage across the switch $S_{A I}$ is equal to DC-link voltage $V_{D C}$ instead of zero. The fault is correctly identified as soon as it happens, so that the $O C F I_{S A I}$ changes from $0 \mathrm{~V}$ to $5 \mathrm{~V}$. Figure 24 shows the experimental test when the open-circuit fault has occurred in $S_{4 L 1}$.

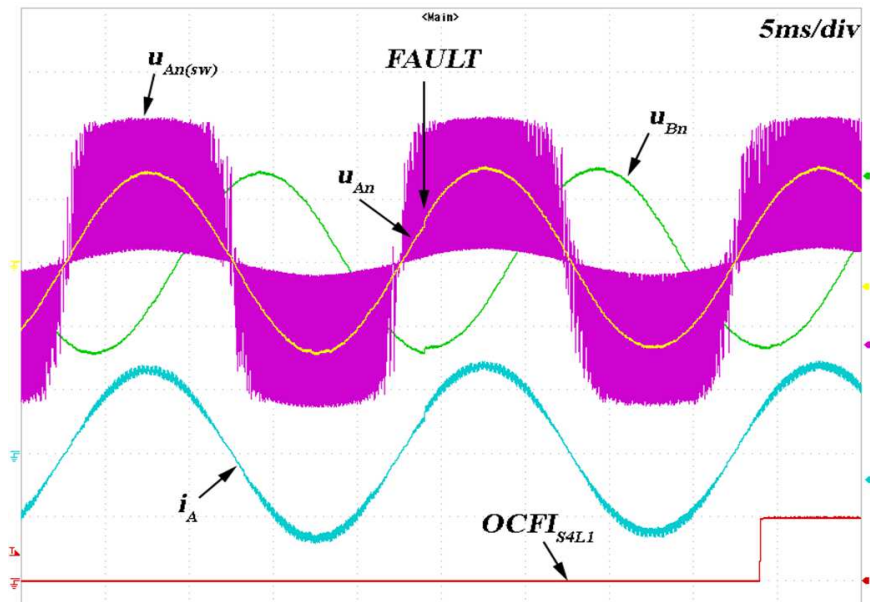

Figure 24: Waveforms under open-circuit fault in $S_{4 L I}$ : a) phase-to-neutral switching voltage $u_{A n(s w)}$ (violet trace, $200 \mathrm{~V} /$ div), b) phase-to-neutral voltages $u_{A n}, u_{B n}$ (yellow trace and green trace, $200 \mathrm{~V} / \mathrm{div}$ ), c) phase current $i_{A}$, (cyan trace, $20 \mathrm{~A} /$ div), d) OCFI (red trace 5V/div).

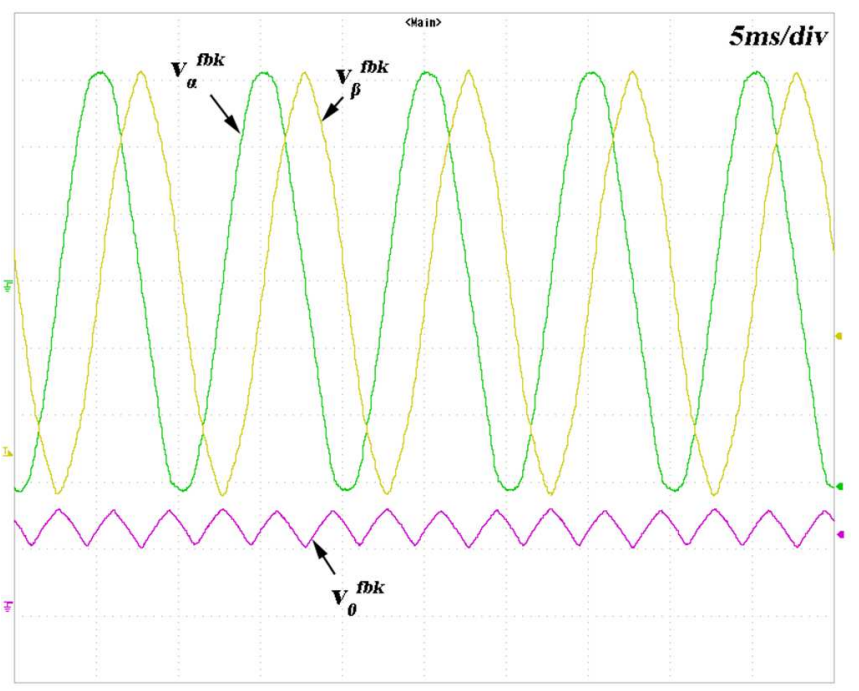

(a)

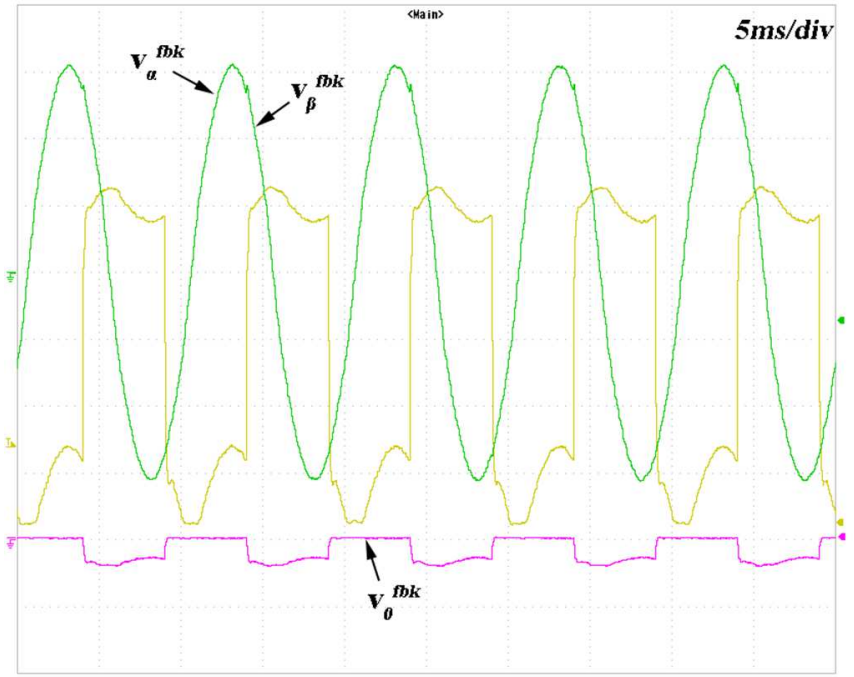

(b)

Figure 25: $\alpha \beta 0$ output voltages $v_{\alpha}^{f b k}, v_{\beta}^{f b k}, v_{0}^{f b k}$ under the open-circuit fault in $S_{A I}$ : a) with RO and b) without RO. $v_{\alpha}^{f b k}$ green trace, $100 \mathrm{~V} / \mathrm{div}, v_{\beta}^{f b k}$ yellow trace, $100 \mathrm{~V} / \mathrm{div}$ and $v_{0}^{f b k}$ violet trace, $400 \mathrm{~V} / \mathrm{div}$. 
In this case, there is only an offset in the phase-to-neutral voltages $u_{A n}, u_{B n}$ and phase current $i_{A}$. Unlike other cases, the fault detection algorithm is able to identify the fault in the subsequent fundamental period, as illustrated in Figure 24. Figure 25 shows the waveform in $\alpha \beta 0$ domain under the opencircuit fault in $S_{A I}$ with and without RO. As it can be seen, the $\mathrm{RO}$ is able to compensate the fault by keeping the $\alpha \beta 0$ output voltages, $v_{\alpha}^{f b k}, v_{\beta}^{f b k}, v_{\theta}^{f b k}$, in pre-failure condition. When the RO is disabled the $\alpha \beta 0$ output voltages are distorted due to the fault. Thus, after the detection of the fault, the fault-tolerant control is applied and, in some cases, the converter can operate feeding the load.

\section{CONCLUSIONS}

This paper presents a novel fault detection and ride/through method for a $3 \Phi 4 \mathrm{~L}$ Inverter in stand-alone applications. The open circuit and short circuit faults of the power semiconductors have been illustrated and the control strategy to detect and manage these faults has been proposed. The performance of the proposed control strategy has been at first verified though a numerical model in Matlab/Simulink. Experimental results to validate the effectiveness of the proposed control strategy are also presented. The results demonstrate that the proposed fault detection and management control method allows to effectively manage open and shortcircuit faults. In summary, the proposed method can maintain the $\alpha \beta 0$ output voltages, $v_{d}^{f b k}, v_{\beta}^{f b k}, v_{\theta}^{f b k}$, under the following conditions:

- when there is one switch open;

- with any two switches open;

- when the $4^{\text {th }}$ leg of the converter has one switch shorted;

when there is a short-circuit fault in the three-phase legs, the faulted half leg should be open, such that it becomes an open circuit fault. Specially, the RO itself can work without knowing exactly the location of the open circuit faults. Existing methods tend to leave-open the whole leg when any of the half leg is open or shorted. However, the proposed method only requires to leave-open the broken half leg, while the healthy half leg can still be used.

\section{REFERENCES}

[1] S. Dasgupta, S. N. Mohan, S. K. Sahoo and S. K. Panda, "Application of Four-Switch-Based Three-Phase Grid-Connected Inverter to Connect Renewable Energy Source to a Generalized Unbalanced Microgrid System," in IEEE Transactions on Industrial Electronics, vol. 60, no. 3, pp. 1204-1215, March 2013.

[2] F. Pulsinelli, M. di Benedetto, A. Lidozzi, L. Solero and F. Crescimbini, "Power Losses Distribution in $\mathrm{SiC}$ Inverter Based Electric Motor Drives," in IEEE Transactions on Industry Applications, vol. 55, no. 6, pp. 7843-7853, Nov.-Dec. 2019.

[3] J. Jung, N. T. Vu, D. Q. Dang, T. D. Do, Y. Choi and H. H. Choi, "A Three-Phase Inverter for a Standalone Distributed Generation System: Adaptive Voltage Control Design and Stability Analysis," in IEEE Transactions on Energy Conversion, vol. 29, no. 1, pp. 46-56, March 2014.

[4] Z. Liu, J. Liu and J. Li, "Modeling, Analysis, and Mitigation of Load Neutral Point Voltage for Three-Phase Four-Leg Inverter," in IEEE Transactions on Industrial Electronics, vol. 60, no. 5, pp. 2010-2021, May 2013.

[5] X. Zhou, J. Sun, H. Li, M. Lu and F. Zeng, "PMSM Open-Phase FaultTolerant Control Strategy Based on Four-Leg Inverter," in IEEE Transactions on Power Electronics, vol. 35, no. 3, pp. 2799-2808, March 2020.
[6] M. A. Rodríguez-Blanco et al., "A Failure-Detection Strategy for IGBT Based on Gate-Voltage Behavior Applied to a Motor Drive System," in IEEE Transactions on Industrial Electronics, vol. 58, no. 5, pp. 16251633, May 2011.

[7] B. Lu and S. K. Sharma, "A Literature Review of IGBT Fault Diagnostic and Protection Methods for Power Inverters," in IEEE Transactions on Industry Applications, vol. 45, no. 5, pp. 1770-1777, Sept.-oct. 2009.

[8] S. Hain and M. Bakran, "Suitable Turn-Off Strategies for IGBTs with a High Desaturation Current During Short Circuit Failures Detected with the 2D-Short Circuit Detection," PCIM Europe 2017; International Exhibition and Conference for Power Electronics, Intelligent Motion, Renewable Energy and Energy Management, Nuremberg, Germany, 2017, pp. 1-7.

[9] S. Ceballos, J. Pou, J. Zaragoza, E. Robles, J. L. Villate, and J. L. Martin, "Fault-tolerant neutral-point-clamped converter solutions based on including a fourth resonant leg," IEEE Trans. Ind. Electron., vol. 58, no. 6, pp. 2293-2303, Jun. 2011.

[10] S. Ceballos et al., "Efficient modulation technique for a four-leg fault tolerant neutral-point-clamped inverter," IEEE Trans. Ind. Electron., vol. 55, no. 3, pp. 1067-1074, Mar. 2008.

[11] U. Choi, J. Lee, F. Blaabjerg and K. Lee, "Open-Circuit Fault Diagnosis and Fault-Tolerant Control for a Grid-Connected NPC Inverter," in IEEE Transactions on Power Electronics, vol. 31, no. 10, pp. 7234-7247, Oct. 2016.

[12] S. Xu, J. Zhang and J. Hang, "Investigation of a Fault-Tolerant ThreeLevel T-Type Inverter System," in IEEE Transactions on Industry Applications, vol. 53, no. 5, pp. 4613-4623, Sept.-Oct. 2017.

[13] W. Zhang and D. Xu, "Fault Analysis and Fault-Tolerant Design for Parallel Redundant Inverter Systems in Case of IGBT Short-Circuit Failures," in IEEE Journal of Emerging and Selected Topics in Power Electronics, vol. 6, no. 4, pp. 2031-2041, Dec. 2018.

[14] E. Jamshidpour, P. Poure and S. Saadate, "Photovoltaic Systems Reliability Improvement by Real-Time FPGA-Based Switch Failure Diagnosis and Fault-Tolerant DC-DC Converter," in IEEE Transactions on Industrial Electronics, vol. 62, no. 11, pp. 7247-7255, Nov. 2015.

[15] M. Eskandari, A. Ahmadi, M. F. Samadi and M. Saif, "Hardware realization of a dq based fault detection scheme for $3 \varphi$ four-leg inverter," 2016 World Automation Congress (WAC), Rio Grande, 2016, pp. 1-6.

[16] M. di Benedetto, A. Lidozzi, L. Solero, F. Crescimbini and P. J. Grbović, "Reliability and Real-Time Failure Protection of the Three-Phase FiveLevel E-Type Converter," in IEEE Transactions on Industry Applications, vol. 56, no. 6, pp. 6630-6641, Nov.-Dec. 2020.

[17] J. O. Estima and A. J. Marques Cardoso, "A new approach for real-time multiple open-circuit fault diagnosis in voltage-source inverters," IEEE Trans. Ind. Appl., vol. 47, no. 6, pp. 2487-2494, Nov./Dec. 2011.

[18] J. O. Estima and A. J. Marques Cardoso, "A new algorithm for real-time multiple open-circuit fault diagnosis in voltage-fed PWM motor drives by the reference current errors," IEEE Trans. Ind. Electron., vol. 60, no. 8, pp. 3496-3505, Aug. 2013.

[19] U.-M. Choi, F. Blaabjerg, and K.-B. Lee, "Study and handling methods of power IGBT module failures in power electronic converter systems," IEEE Trans. Power Electron., vol. 30, no. 5, pp. 2517-2533, May 2015.

[20] A. Lidozzi, M. Di Benedetto, S. Bifaretti, L. Solero and F. Crescimbini, "Resonant Controllers With Three Degrees of Freedom for AC Power Electronic Converters," in IEEE Transactions on Industry Applications, vol. 51, no. 6, pp. 4595-4604, Nov.-Dec. 2015.

[21] M. Tang, A. Formentini, S. A. Odhano and P. Zanchetta, "Torque Ripple Reduction of PMSMs Using a Novel Angle-Based Repetitive Observer," in IEEE Transactions on Industrial Electronics, vol. 67, no. 4, pp. 26892699, April 2020.

[22] G. Lo Calzo, A. Lidozzi, L. Solero and F. Crescimbini, "LC filter design for on-grid and off-grid distributed generating units," in IEEE Transactions on Industry Applications, vol. 51, no. 2, pp. 1639-1650, March-April 2015.

[23] M. di Benedetto, A. Lidozzi, L. Solero, F. Crescimbini and P. J. Grbović, "Design of High-Power Density Interleaved 3-Phase 5-Level E-Type Back-to-Back Converter," 2020 IEEE Energy Conversion Congress and Exposition (ECCE), 2020, pp. 3957-3964.

[24] M. L. Mendola, M. di Benedetto, A. Lidozzi, L. Solero and S. Bifaretti, "Four-Port Bidirectional Dual Active Bridge Converter for EVs Fast Charging," 2019 IEEE Energy Conversion Congress and Exposition (ECCE), 2019, pp. 1341-1347. 